\title{
Voorwoord bij het themanummer functionele urologie: wat is nieuw in functionele urologie en urogynaecologie?
}

\author{
John P. F. A. Heesakkers - Jan-Paul Roovers - Bertil F. M. Blok
}

Geaccepteerd op: 5 juli 2021 / Published online: 17 augustus 2021

(C) The Author(s) 2021

De laatste keer dat er een themanummer over functionele urologie in het Tijdschrift voor Urologie werd gepubliceerd was in 2014. Er is in die zeven jaar veel veranderd. Waar vroeger de meeste urologen van mening waren dat de functionele urologie er wel bij gedaan kon worden, is er tegenwoordig een duidelijke trend naar subspecialisatie. Hierbij is de verbinding met aanpalende disciplines, zoals de gynaecologie, essentieel voor een optimale behandeling.

Volgens de richtlijnen heeft intermitterende katheterisatie de voorkeur boven een verblijfskatheter. Berendsen et al. presenteren de gegevens over blaaskatheterisatie van de Vektis-GIPdatabank van alle 17 miljoen verzekerde Nederlanders in de laatste 20 jaar. Voor het eerst worden het gebruik en de kosten van wegwerp- en verblijfskatheters inzichtelijk gemaakt.

Centraal in de conservatieve behandeling van de overactieve blaas staat de medicamenteuze behandeling. Witte en Michel geven een compleet overzicht op het gebied van anticholinergica en $\beta 3$-agonisten. Met name van de laatste groep komt binnenkort een aantal nieuwe medicamenten op de markt. Ook worden de toekomstige ontwikkelingen vanuit commercieel perspectief besproken.

Sacrale neuromodulatie is zonder meer een van de belangrijkste derdelijns behandeltechnieken voor blaasfunctiestoornissen. Janssen en Smits beschrijven de huidige ontwikkelingen met betrekking tot optima-

prof. dr. J. P. F. A. Heesakkers

afdeling Urologie, MUMC+, Maastricht, Nederland

prof. dr. J.-P. Roovers

afdeling Gynaecologie, Amsterdam UMC, Amsterdam, Nederland lisatie van patiëntenselectie en chirurgische techniek en gaan uitgebreid in op een aantal technische verbeteringen, waarbij de introductie van de MRI-compatibele oplaadbare batterij met een levensduur van minimaal 15 jaar het meest in het oog springt.

Dat synthetische matjes problemen kunnen geven, is intussen bekend bij elke behandelaar die zich met vrouwelijke stressurine-incontinentie en vaginale verzakkingen bezighoudt. Hoe het allemaal zo gekomen is, kunt u lezen in het artikel van Heesakkers et al. De auteurs zetten op een rij welke complicaties zijn beschreven na plaatsing van de polypropyleen tapes en, wellicht belangrijker, welke alternatieven er nu en in de toekomst zijn voor de behandeling voor stressincontinentie bij de vrouw.

Tot slot een persoonlijke visie van Martens en Cornel op de chirurgische behandeling van stressurineincontinentie bij de man: er is duidelijk behoefte aan uniforme uitkomstmaten. Ook bespreken zij kritisch een recent gepubliceerde gerandomiseerde vergelijkende studie tussen de kunstsfincter en mannelijke synthetische tape en doen aanbevelingen ter optimalisatie van de behandeling.

Open Access This article is distributed under the terms of the Creative Commons Attribution 4.0 International License (http://creativecommons.org/licenses/by/4.0/), which permits unrestricted use, distribution, and reproduction in any medium, provided you give appropriate credit to the original author(s) and the source, provide a link to the Creative Commons license, and indicate if changes were made.

prof. dr. John P.F.A. Heesakkers, uroloog

prof. dr. Jan-Paul Roovers, gynaecoloog

dr. Bertil F.M. Blok, uroloog 